\title{
Flight Experiment Verification of Shuttle Boundary Layer Transition Prediction Tool
}

\author{
Scott A. Berry ${ }^{1}$, Karen T. Berger ${ }^{2}$, Thomas J. Horvath', and William A. Wood ${ }^{3}$ \\ NASA Langley Research Center, Hampton, VA 23681
}

\begin{abstract}
Boundary layer transition at hypersonic conditions is critical to the design of future high-speed aircraft and spacecraft. Accurate methods to predict transition would directly impact the aerothermodynamic environments used to size a hypersonic vehicle's thermal protection system. A transition prediction tool, based on wind tunnel derived discrete roughness correlations, was developed and implemented for the Space Shuttle return-to-flight program. This tool was also used to design a boundary layer transition flight experiment in order to assess correlation uncertainties, particularly with regard to high Mach-number transition and tunnel-to-flight scaling. A review is provided of the results obtained from the flight experiment in order to evaluate the transition prediction tool implemented for the Shuttle program.
\end{abstract}

\section{Nomenclature}

\begin{tabular}{|c|c|c|c|}
\hline $\operatorname{Re}_{\theta}$ & $\begin{array}{l}\text { momentum thickness Reynolds number, } \\
\rho_{\mathrm{e}} u_{\mathrm{e}} \theta / \mathrm{u}_{\mathrm{e}}\end{array}$ & $\begin{array}{l}\mathrm{m} \\
\rho\end{array}$ & $\begin{array}{l}\text { protuberance correlation power } \\
\left.\text { density (slug/ } \mathrm{ft}^{3}\right)\end{array}$ \\
\hline \multirow[t]{2}{*}{$\operatorname{Re}_{\mathrm{k}}$} & Reynolds number evaluated at trip height, & U & velocity (ft/s) \\
\hline & $\rho_{\mathrm{k}} u_{\mathrm{k}} \mathrm{k} / \mu_{\mathrm{k}}$ & $\mu$ & viscosity (slug/ft-s) \\
\hline M & Mach number & $\mathrm{T}$ & Temperature \\
\hline $\mathrm{k}$ & trip or protuberance height (in) & \multicolumn{2}{|c|}{ Subscripts } \\
\hline$\delta$ & boundary layer thickness (in) & $\infty$ & freestream conditions \\
\hline$\theta$ & momentum thickness (in) & $\mathrm{e}$ & boundary layer edge conditions \\
\hline $\mathrm{H}$ & total enthalpy & W & wall conditions \\
\hline$\sigma$ & correlation coefficient & $\mathrm{k}$ & protuberance height conditions \\
\hline
\end{tabular}

\section{Introduction}

Thermal management is the predominant issue of hypersonics. Due to extreme post-shock temperatures and surface shear stresses that result from hypersonic velocities within the atmosphere, a thermal protection system (TPS) is essential for all reentering spacecraft. Fortunately, a boundary of fluid envelops the vehicle and acts as a buffer, reducing the post-shock conditions to more manageable levels near the vehicle surface. Initially this boundary layer starts out as laminar, which can be thought of as orderly layers (or laminates) of fluid. Eventually the increasing atmospheric density and/or the vehicle surface roughness induces chaotic mixing of the layers, or turbulence, which contributes to increased convection of energy to the surface. Being able to predict when the boundary layer will transition from a laminar to a turbulent state, which results in a significant increase in convective heat transfer to the surface (perhaps over four times higher), becomes paramount to the vehicle design problem. To circumvent the issue of having an accurate method of boundary layer transition (BLT) prediction, TPS designers have in the past typically adopted conservative approaches, such as using an allturbulent heating profile to select material and size thickness. The "all-turbulent" approach, which ultimately means a thicker TPS and heavier design, was utilized for $\mathrm{X}-34^{1}$ and more recently for the Orion Multi-Purpose

\footnotetext{
${ }^{1}$ Research Scientist, Aerothermodynamics Branch, MS 408A, AIAA Associate Fellow.

2 Research Scientist, Supersonic/Hypersonic Testing Branch, MS 408A, AIAA Senior Member.

${ }^{3}$ Branch Head, Aerothermodynamics Branch, MS 408A, AIAA Associate Fellow.
} 
Crew Vehicle, which was formerly known as the Crew Exploration Vehicle. ${ }^{2}$ Having an accurate BLT prediction methodology could allow for decreased conservatism and weight (or increased payload) in the design of future space flight programs.

Significant progress has been made in recent years to understand the physical mechanisms of the hypersonic BLT process, which can be characterized by understanding the presence and growth of waves within the laminar boundary layer. Waves develop from perturbations to the orderly layers of fluid, and these initially small disturbances grow or dampen depending on the local stability of the wave motion. Semi-empirical predictive methods have been available for years for simple problems with linear processes, but recent advancements are now addressing the nonlinear breakdown processes on three-dimensional geometries, including real-gas effects and roughness (see for example Ref. 3). Even with these advancements in a theoretical basis for predicting boundary layer transition, implementation of these methods as part of a vehicle design process is not yet stateof-the-art. The Shuttle program required an easy-to-use prediction methodology to support mission operation decisions, to allow rapid on-orbit inspection and assessment of TPS damage sites. ${ }^{4-10}$ The use of a physics-based approach was ultimately not implemented in support of Shuttle due to the complexity of the problem. For instance, the extensive computational database that was used for Shuttle mission support was populated with only smooth surface solutions, which would not have been sufficient for analyzing the instability processes due to surface roughness on the Shuttle. Current state-of-the-art in computational capability is not quite ready to deal with the enormous number of tile steps and gaps of the Shuttle windward surface.

Most, if not all, flight vehicles have surface features that can be characterized as significant roughness and thus provides a by-pass mechanism to the smooth wall transition process. Thus, surface roughness, as dictated by the state of the TPS, plays an integral role in determining the probable transition onset time during reentry. Roughness can be divided into two categories, distributed and discrete. Distributed roughness is characteristically small and abundant, and is usually inherent to the TPS. Discrete roughness is typically inadvertent. It is much larger in scale than distributed roughness and is isolated or infrequent. Most spacecraft designed for reentry have some form of inherent distributed surface roughness. On Shuttle Orbiters, the distributed roughness is due to the (slight misalignments of) steps and gaps between the many ceramic TPS tiles. In the case of TPS designed for planetary entry or lunar return, distributed roughness can be formed on the surface during entry by spallation and/or ablation due to extremely high surface temperatures. Traditional ceramic-based TPS tiles such as those used on the Orbiters are also susceptible to inadvertent (discrete) roughness such as damage from launch in the form of cavities and/or gap filler protrusions. For the Space Shuttle Orbiters, the background distributed roughness (tile-to-tile steps and gaps) will induce boundary layer transition at a Mach number on the order of 8 (or less), as long as no large discrete trips are present. On two occasions (STS-28 and STS-73), the Orbiters experienced early boundary-layer transition at Mach numbers nearer to 18 due to a discrete roughness as a result of large protruding gap filler. ${ }^{20}$ Historically, on the order of $10 \%$ of flights have experienced "early" BLT, which is considered as Mach 12 or higher."

As part of the Space Shuttle return-to-flight (RTF) effort, a damage assessment process, which included a BLT prediction tool, was developed and implemented for the final 22 flights of the program. References 4-10 provide details of the BLT Tool, both versions 1 and 2, including the ground-based data, computational approach, and historical flight data used as calibration. As discussed in Ref. 8, there were some significant ambiguities regarding the historical calibration data. During STS-114, the program chose to conduct an unprecedented spacewalk repair to remove 2 large gap filler protrusions rather than risk the predicted (but uncertain) early BLT, which was much earlier than prior history. ${ }^{9}$ To reduce uncertainties with the BLT Tool prediction at high Mach number, the BLT Flight Experiment (FE) was proposed and accepted by the program. References 12,13, and 14 provide background, operational details, and initial results of the BLT FE, which ultimately ended up as a five-flight incremental approach to determine if there was a limit to how early BLT can occur at hypersonic conditions. Another goal was to determine if ground-to-flight scaling effects were an important consideration in the development of discrete roughness correlations. The present paper is intended as a final review of all five flights in order to compare the BLT Tool predictions to well-controlled (high quality) flight data to assess correlation uncertainties. 


\section{Shuttle BLT}

Orbiter reentries represent the most comprehensive dataset of available hypersonic flight boundary layer transition results with 135 missions flown over a 30 -year period providing a good statistical reference with which to reveal the complexity of the problem. BLT onset varies with every mission based largely on the surface roughness characteristics that are highly dependent upon the state of the TPS determined after launch. This complicates the analysis of this flight data as the roughness characteristics prior to entry are typically not known, nor is it controlled in any way during entry. Adding to the complexity is the lack of detailed and

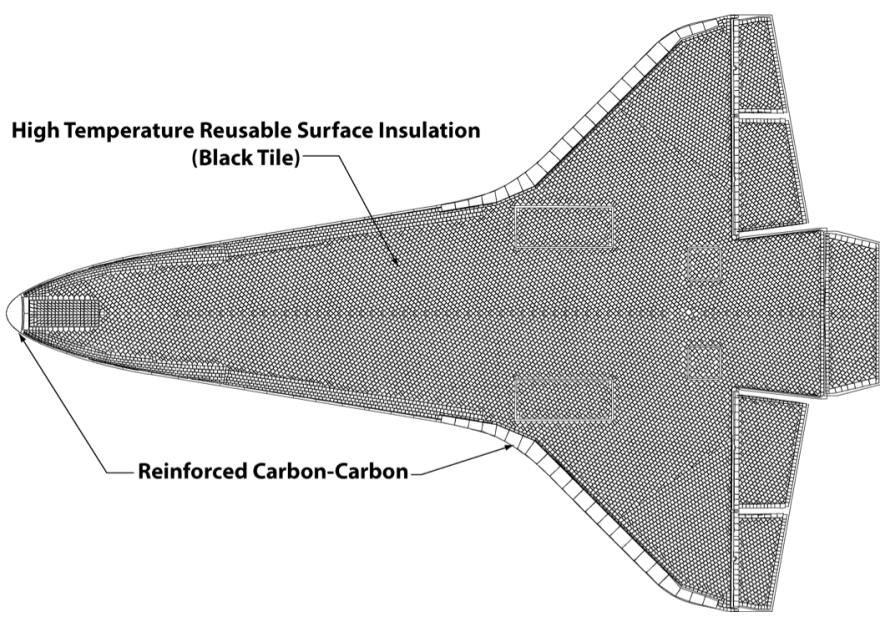
consistent information on the as-flown surface

Figure 1. Shuttle Windside Surface TPS Layout. condition that has been recorded after each flight. Figure 1 provides a sketch of the windward surface TPS layout, which is primarily dominated by the roughly 24,000 black ceramic tiles along with gap fillers that are used to fill out-of-tolerance gaps. Typically after every mission, anywhere from 30 to 100 tiles (and gap fillers) are replaced for damage or other reasons. Even with these shortcomings, the Shuttle dataset provides valuable insight into BLT at hypersonic flight conditions, even though local conditions at the trip are actually supersonic due to its large angle of attack during entry. While much of the specific data from each of these missions are not available to the general public, a great deal of the boundary layer transition results have been reviewed and summarized over the years. One of the first reports to provide details regarding BLT results from the first few missions was by Lee and Harthun ${ }^{15}$ and was quickly followed by Goodrich, et al., ${ }^{16}$ which provided an initial attempt to look at simple engineering type correlations. Poll ${ }^{17}$ provided a different approach to developing a useful correlation from the Shuttle flight data, which was specific to attachment line transition. Later, Hartung and Throckmorton ${ }^{18}$ provided a detailed analysis of the first five flights showing the global movement of BLT during entry. In the early 1990s, Bouslog, et al. ${ }^{19}$ provided a BLT summary of the first 32 flights, which was then later updated..$^{20}$ More recently, McGinley, et al. ${ }^{8}$ provided an in-depth review of all available sources for Shuttle BLT data from the first 100 or so flights. Some more recent flight data and results have also been published by Berry, et al., 91,22

\section{BLT Tool Development}

Starting in early 2004, in response to the Columbia Accident Investigation Board directive to develop onorbit TPS inspection and repair capabilities as part of the RTF effort, ${ }^{23}$ a team was assembled to address the difficult problem of providing a suitable method to predict BLT. This team included prominent national experts in the field from the government, industry, and academia. Although consensus was difficult, the team adopted a discrete roughness approach that showed promise with prior ground-based testing (see Ref. 20, 24, and 25). Through a focused and coordinated effort that combined new comprehensive ground-based data with a consistent computational method, and included a detailed review of the best flight BLT data available, BLT Tool V1 was ready in time for the first RTF mission (STS-114) in July 2005. ${ }^{4-8}$ The tool provided the capability to assess both gap filler protrusions as well as cavities from TPS damage or gouges. Further refinement of the data (including new high-enthalpy results) and analysis led to the BLT Tool V2 (see Ref. 10 and 26), which was the version used on all subsequent missions and to size the trips for the sequence of BLT FE flights.

A brief review of the protuberance correlations implemented for BLT Tool V2 is provided for reference. The tool was set up to interrogate an extensive high-fidelity Navier-Stokes computational database of trajectory solutions (including nonequilibrium chemistry effects) to extract the boundary layer (BL) properties needed at any point on the windward surface of the Shuttle. Then based on a given damage site location and dimensions, these BL properties would be combined and compared against primary and secondary correlations, to estimate BLT onset. As part of the tool development peer review process, it was decided that multiple correlations were to be used in order to assess prediction uncertainties. To develop the correlations, a regression analysis was 
used throughout to establish upper and lower limits that represent the $95 \%$ confidence intervals of each respective dataset. In the discussion to follow, "best fit" represents the mean of the data, while the bounds $( \pm 95 \%$ line) represent a conservative capture of all the wind tunnel experimental results. The two protuberance correlations, one based on $\mathrm{Re}_{e} / \mathrm{M}_{\mathrm{e}}$ and one based on $\mathrm{Re}_{\mathrm{k}}$, are shown in Fig. 2. Note that the correlations and bounds shown represent the recommended implementation, which shifted the best fit and bounds of the correlation to match the trends observed from the historical flight data. There will be further discussion of the bias between wind tunnel and flight toward the end of the paper.

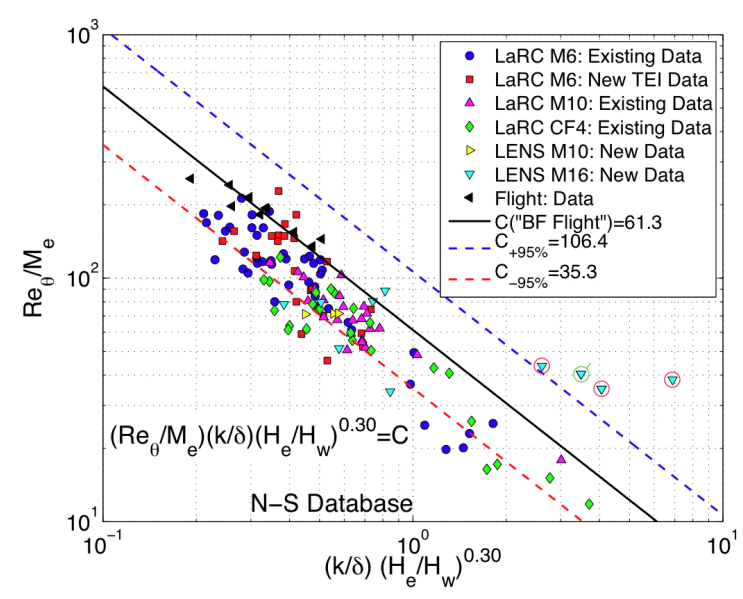

a) $\operatorname{Re}_{\mathrm{e}} / \mathrm{M}_{\mathrm{e}}$ correlation.

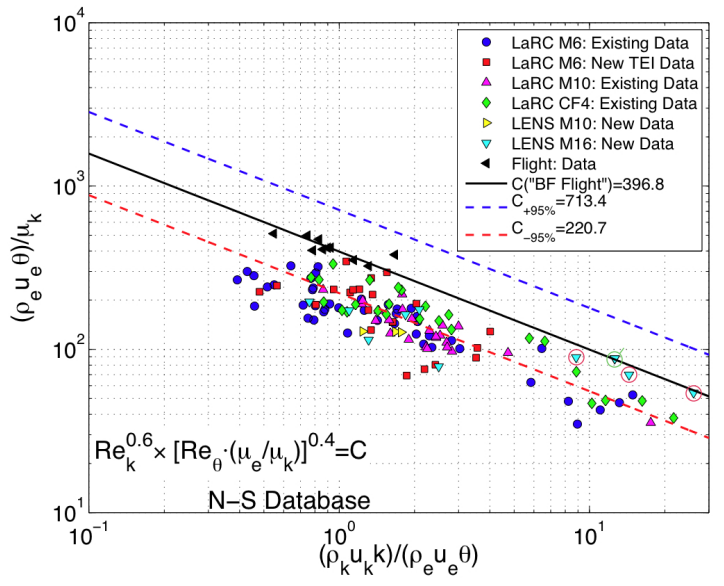

b) Re $_{k}$ correlation.

Figure 2. Final protuberance correlations recommended for BLT Tool V2.

\section{Flight Experiment Overview}

Due to the STS-114 experience, which dealt with large uncertainties associated with BLT predictions early in the flight trajectory (i.e., at high Mach numbers), the BLT FE project was proposed in November 2006. ${ }^{12}$ The project was specifically formulated to utilize some of the remaining Shuttle flights as a test bed to purposefully trip the boundary layer at prescribed Mach numbers. The trip location was selected to be on the port wing, as shown in Fig. 3, based on consideration of thermal and structural margins, the chance for debris impacts, and availability of extra instrumentation channels and wiring. The region of the wing to be influenced by turbulence from the trip is represented in Fig. 3 by the noted wedge.

The protuberance shape utilized for the project is shown in Fig. 4. This shape was selected after careful consideration of the aerothermal and structural aspects of several designs (see Ref. 13). Each BLT FE trip was built integral to a standard tile with the protuberance height set at the appropriate amount for each incremental case. To minimize the amount of vehicle processing beyond the operational norm, the project utilized Space Shuttle Orbiter Discovery for the first four BLT FE flights, STS-119, STS-128, STS-131, and STS-133, and Space Shuttle Endeavour for the final mission on STS-134. Additional instrumentation was installed in order to obtain more spatially resolved measurements downstream of the protuberance. A notional sketch of the instrumentation layout for all 5 missions is shown in Fig. 5.

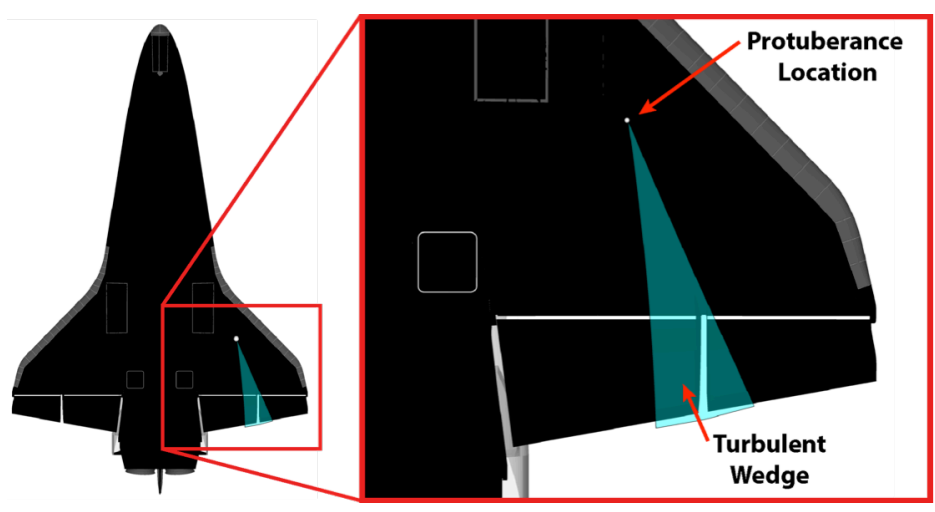

Figure 3. Selected protuberance location and predicted turbulent wedge. 


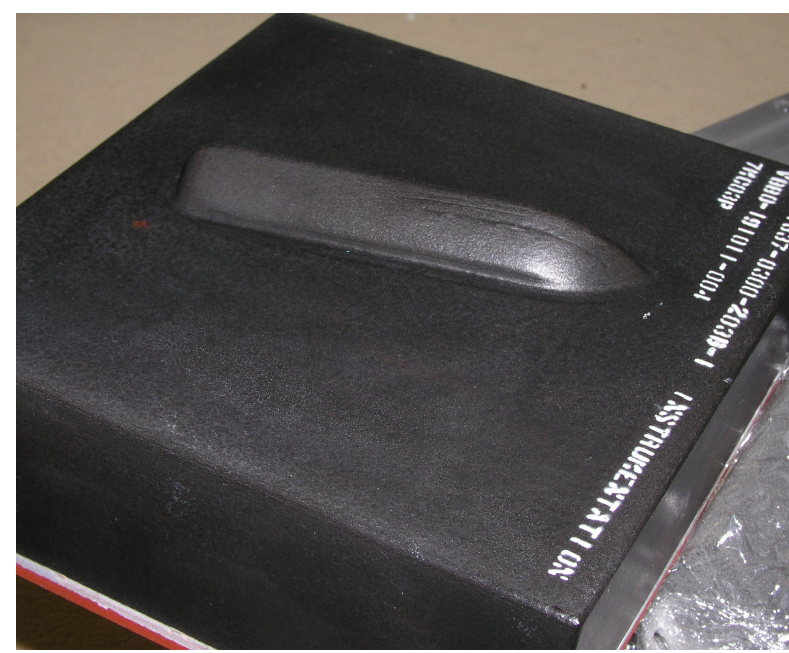

Figure 4. Photo showing the BLT FE trip built into a Shuttle tile.

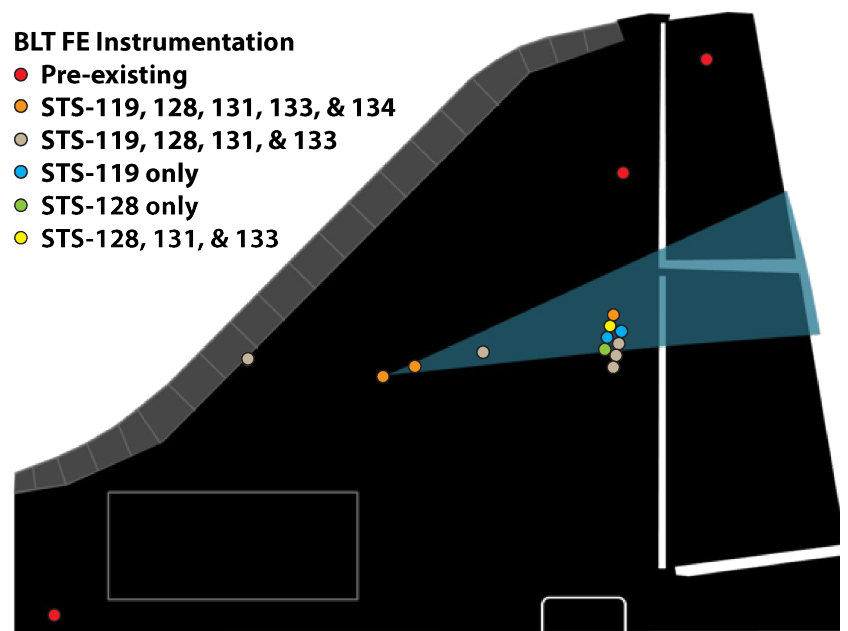

Figure 5. Layout showing added BLTFE instrumentation.

An incremental flight envelope expansion approach involving increasing protuberance height was utilized for the BLT FE. The first flight, STS-119, targeted a BLT onset of approximately Mach 15 in order to be sufficiently above the range of normal vehicle BLT onset that interpretation of the flight data would be easier. The second and third flights on STS-128 and STS-131 targeted approximately Mach 18, with the intent of approaching the earliest flight historical BLT onset Mach numbers, experienced during STS-28 and STS-73. The fourth and fifth flights, STS-133 and STS-134, targeted approximately Mach 19.5, with the intent of exceeding flight experience so that the results would be statistically significant relative to prediction uncertainty. The height of the protuberance was derived using the Orbiter BLT Tool, Version 2 with a $\mathrm{Re}_{\mathrm{e}} / \mathrm{Me}_{\mathrm{e}}$ versus $(\mathrm{k} / \delta)\left(\mathrm{H}_{\mathrm{e}} / \mathrm{H}_{\mathrm{w}}\right)^{0.3}$ methodology using a best estimate correlation coefficient established from historical Orbiter flight data. The flown protuberance height was 0.25 in for STS-119, 0.35 in for both STS- 128 and STS-131 and 0.5 in for STS-133 and STS134. As preparation for each flight, aerothermal, thermal, and stress analyses were performed for the protuberance, the area immediately surrounding the protuberance, and the downstream regions within and immediately surrounding the turbulent wedge.

\section{Results \& Discussion}

As discussed in Ref 27, a supplemental activity to provide remote thermal imagery of Space Shuttle reentries with the BLT FE was also supported by the Shuttle program and NASA Engineering and Safety Center (NESC). The Hypersonic Thermodynamic Infrared Measurements (HYTHIRM) project at NASA Langley was formulated in 2007 to augment the discrete temperature measurements of the on-board thermocouples with higher resolution infrared (IR) derived surface temperatures at targeted Mach numbers. Whereas the thermocouple (TC) data provides a complete temporal history for select (but limited) locations, the HYTHIRM images complement with high spatial-density data for a limited portion of the trajectory. HYTHIRM was intended to provide a high-resolution "snap-shot in time" to potentially fill in the blanks between the TCs. The HYTHIRM project formally supported 7 shuttle reentries (STS-119, 125, 128, 131, 132, 133, and 134), 5 of which were the BLT FE flights (to be discussed next). References 28 and 29 provide additional details about the logistics, analyses, and results of all the HYTHIRM collected data, while Ref. 30 provides details regarding the post-flight process to convert 2D IR imagery into calibrated 3D mapped temperatures on the surface of an Orbiter CAD file (the results used for the present paper).

For the five BLT FE missions to be discussed next, the HYTHIRM results will be used to establish the global view in comparison to the thermocouple data, and then the transition onset times will be identified. The final section will seek to establish how well the BLT Tool performed in comparison to the BLT FE results. Note that in the discussion to follow that the preexisting instrumentation is referred to as the Modular Auxiliary Data System (MADS) and the newly added sensors are referred to as the BLT FE instrumentation. 


\section{STS-119}

The first flight supporting the BLT FE was STS-119, a 12-day mission that landed March 28, 2009. The trip height was 0.25 in for this mission. Based on the pre-flight trajectory and the BLT Tool V2 correlations, the BLT FE was expected to initiate transition at a Mach number near 15.4. For STS-119, the HYTHIRM team used a Navy P-3 Orion (Cast Glance) to fly near the ground track during reentry. The image shown in Fig. 6 provides the spatially mapped IR image for STS119 , captured at Mach $8.4(\sim \mathrm{t}=1195 \mathrm{~s})$. The body flap is deflected at roughly 2 deg at the time this image was taken. This STS-119 image revealed two features of note, to be discussed next.

First is the prominent turbulent wedge that starts near the nose and is skewed towards the starboard side of centerline. This was an unexpected asymmetric boundary-layer

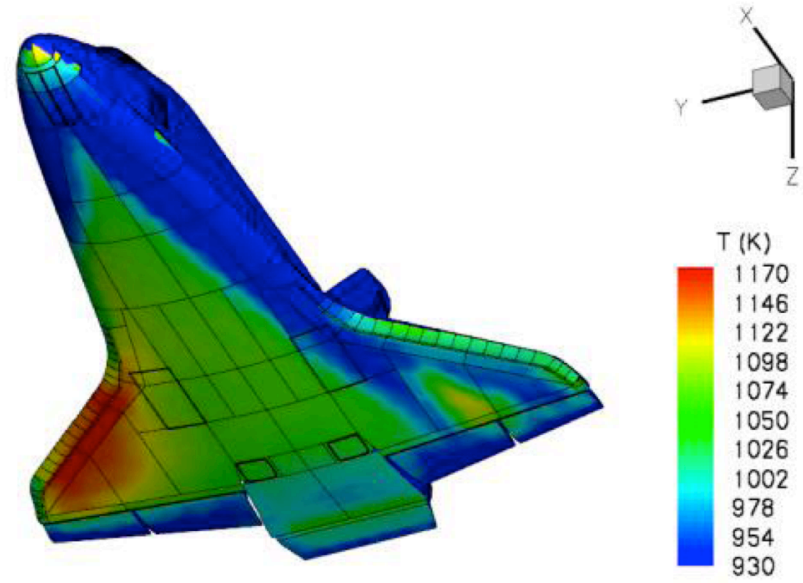

Figure 6. HYTHIRM 3D Mapped Image for STS-119, captured at Mach 8.4 transition (ABLT) event. The post-flight runway inspection did not identify the source for this turbulent wedge, but based on detailed post flight analysis it was thought to be on the order of a 0.18 in gap filler protrusion just to the starboard side of and roughly 20 tiles behind the nose landing gear door. The missing gap filler likely fell out on the runway prior to inspection. From the TC data (published previously in Ref. 13), the starboard side experienced transition at 1127s after entry, or at Mach 10.4. The port side saw transition flash forward at roughly 1216s, or Mach 7.9. These transition onset times, as interpreted from the pre-existing TC time history data, are reflected in Fig. 7. It is worth noting that while the TC data provides a complete time history for the select body points, the high-resolution image provided the most insight into possible locations for a post flight analysis of the asymmetric wedge.

The second feature is the smaller port-wing turbulent wedge from the BLT FE. Based on the data obtained from the new port-wing instrumentation ${ }^{13}$, the time of transition onset for the trip was roughly $969 \mathrm{~s}$, or at Mach 15.6. This result was slightly earlier in time (or higher in Mach number) than pre-flight predictions, but well within accepted uncertainty. The new instrumentation was located to not only identify transition onset, but also the wedge angle for a fully effective trip. Figure 8 shows the end results, with transition onset at $t=969 \mathrm{~s}$ and a fully effective wedge at roughly $t=1045 \mathrm{~s}$. The wedge half angle, as measured from TC\#1 (the assumed wedge

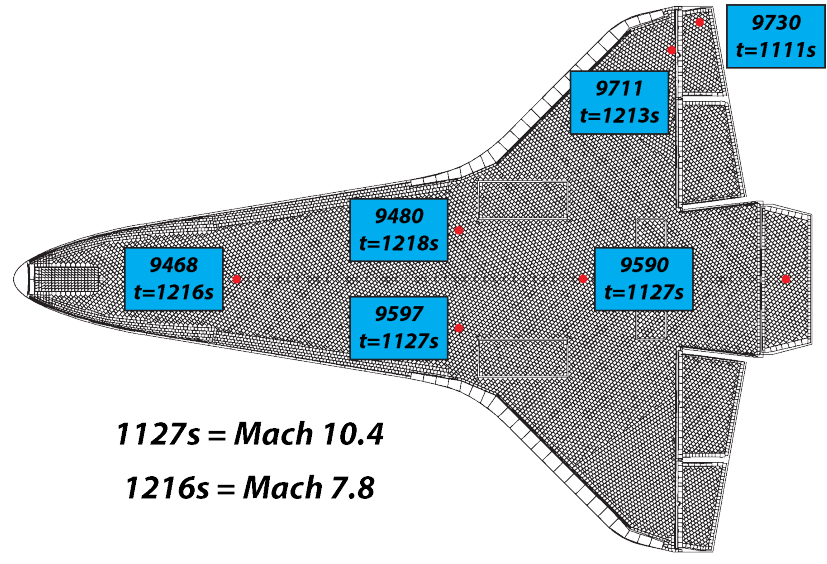

Figure 7. Transition onset times from the MADS data for STS-119.

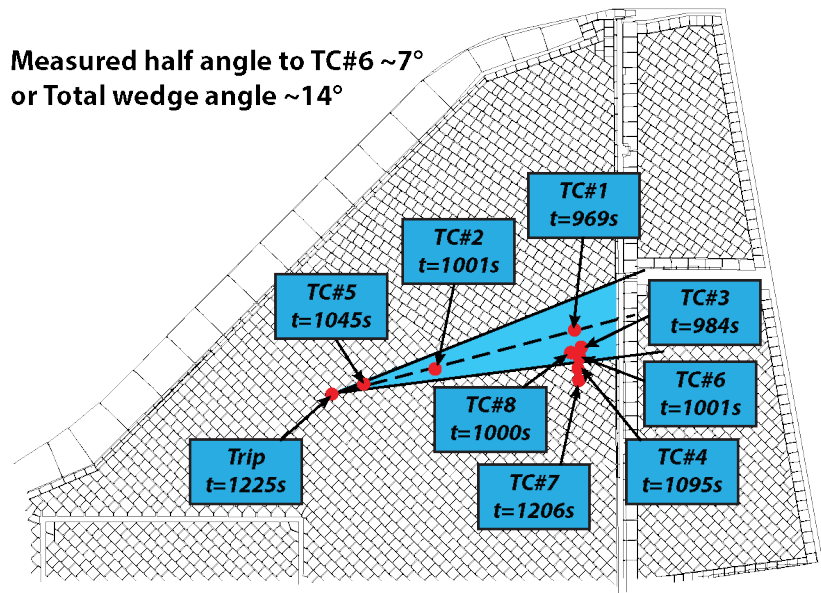

Figure 8. Transition onset times from the BLT FE instrumentation for STS-119.

6

American Institute of Aeronautics and Astronautics 
centerline) to the outside of TC\#6 is roughly 7 deg, or 14 deg for the total wedge angle. The rest of the thermocouples reflect transition at about the same time that the port side flashed turbulent. Thus, the image shown in Fig. 5 was perfectly timed to observe the turbulent wedge from both the BLT FE and the unexpected asymmetric event, as another few seconds ( 25s or so) the vehicle would have been mostly turbulent.

\section{STS-128}

The second BLT FE flight was STS-128, a 13day mission that landed September 11, 2009 and was also on OV-103 (Discovery). STS-128 provided the first incremental trip height increase, to $k=0.35$ in (with the expected time of transition onset nearer to the previous earliest experience of Mach 18). HYTHIRM used the same airborne IR asset (P-3) to capture imagery, this
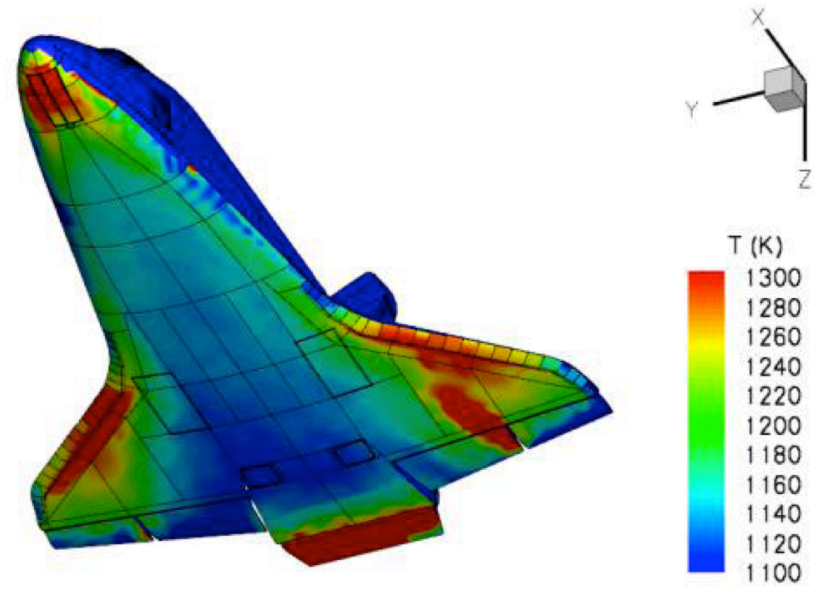

Figure 9. HYTHIRM 3D Mapped Image for STS-128, captured at Mach 14.7.

time at an earlier point in the trajectory. Figure 9 provides the STS- 128 spatially mapped 3D image, captured at Mach 14.7. Elevated heating from the tripped turbulent flow from the BLT FE is seen on the port wing (the lower right side of the image). The rest of the vehicle is laminar at this flight condition, although high heating is also seen on the deflected body flap, which from the telemetry data was deflected at 7.5 deg into the flow at the time of this image.

The transition times determined from the standard MADS data are shown in Fig. 10. As first mentioned in Ref. 13, this flight also experienced an early asymmetric BLT event, this time on the port side of the vehicle with 4 TCs showing onset at roughly 1040s or Mach 13.6. The forward and starboard TCs showed onset later, at a more nominal Mach number near 8.3. The runway inspection did not find any protruding gap fillers that could be linked as the source for this ABLT event, however, a tile-to-tile step was noted. Further analysis showed that the location of this forward facing step as the leading candidate, although the noted step height ( 0.15 in) was a little low (but within uncertainty bounds) to match the observed time (should have been closer to Mach 9.6). Fortunately, the port side asymmetric transition event did not obscure the fully effective wedge for the BLT FE.

The transition times determined from the BLT FE instrumentation are shown in Fig. 11. The TC traces for this flight can be found in Ref. 13. For STS-128, transition onset for the BLT FE was identified as $t=916 \mathrm{~s}$ (Mach 17.3)

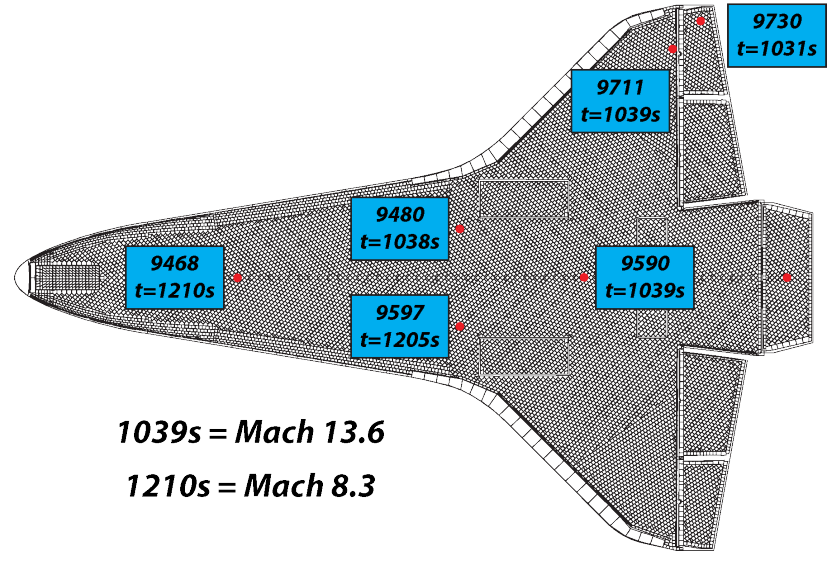

Figure 10. Transition onset times from the MADS data for STS-128.

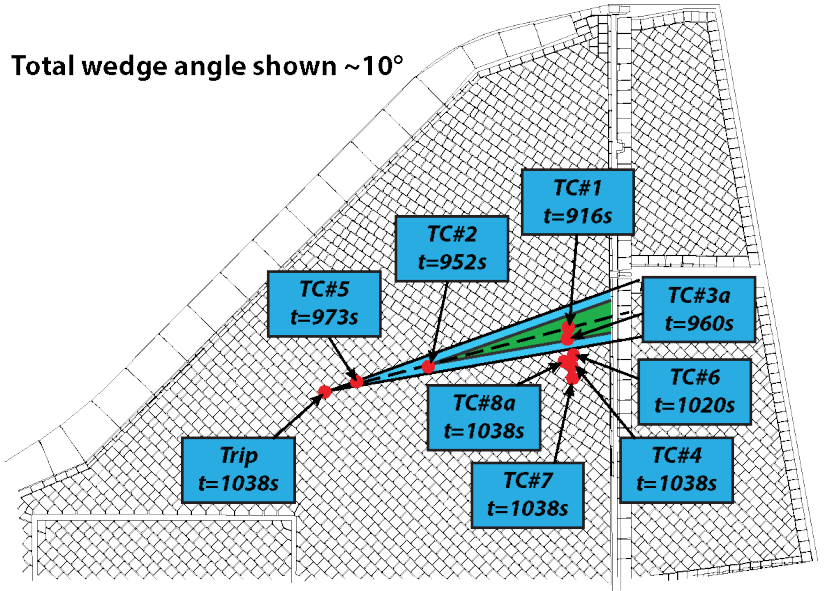

Figure 11. Transition onset times from the BLT FE instrumentation for STS- 128. 
and was fully effective at around $t=970$ s (Mach 15.8). As noted by Ref. 13, the turbulent wedge was "initially very narrow," more so than expected based on the previous flight. A 10-deg wedge is shown in Fig. 10, as it best seems to fit the cascading transition onset times (initially connecting TC\#2 to TC\#3a, and later TC\#5 to just inboard of TC\#6).

Due to the limited number of new thermocouple channels available to support the BLT FE, the decision was made early in project formulation to assume symmetry and distribute the locations to more accurately capture only one side of the turbulent wedge. It is possible that maneuvers during reentry could contribute to the wedge moving to either side of the assumed centerline. For STS-128, the angle of attack, yaw, and roll were nominal for most of the trajectory, with only slight and short duration deviations in the time frame of interest to the BLT FE. These

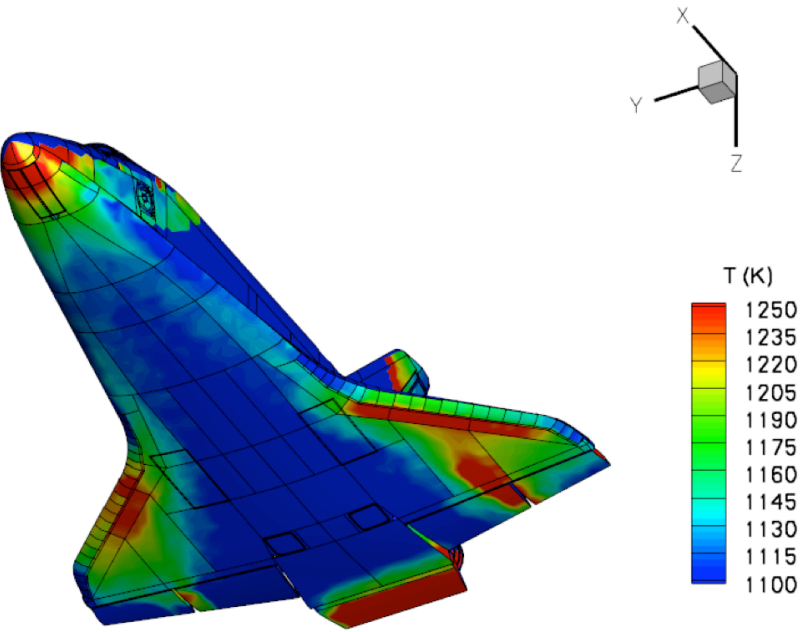

Figure 12. HYTHIRM 3D Mapped Image for STS-131, captured at Mach 15.

quick departures might have contributed to momentary shifting of the wedge, but it is not likely that the shift could have been sustained. For this reason, the smaller wedge is believed to be a real observation, showing the effect of tripping at higher Mach numbers.

\section{STS-131}

The third BLT FE flight was STS-131, a 15-day mission that landed April 20, 2010, and also on OV-103 (Discovery). The BLT FE trip height was again 0.35 in, a repeat of the previous mission. For STS-131 the HYTHIRM team used two land-based infrared systems that were prepositioned to sites below expected ground tracks, which for this mission was over the continental US (CONUS). The IR imagers, owned and operated by the Clay Center Observatory (out of Boston, MA), were referred to as Mobile Aerospace Reconnaissance Systems (MARS). One system, designated as MARS-1, was transported to various mid-CONUS sites on a small NASA aircraft, a Beechcraft UC-12, while the other, MARS-2, was driven in a small van to different sites. The UC-12 provided mission flexibility for rapid repositioning of MARS-1 over large distances, in case of significant deorbit delays. As it turned out for the day of landing, MARS-2, located in Hot Springs, AZ was in position (after a one-orbit wave off due to landing site weather) and captured at Mach 15 the image shown in Fig. 12. Note the similarities between

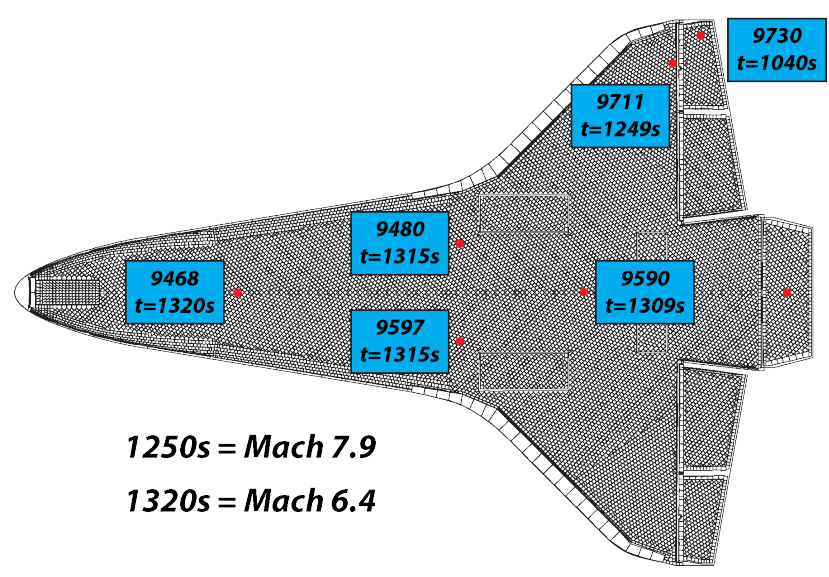

Figure 13. Transition onset times from the MADS data for STS-131.

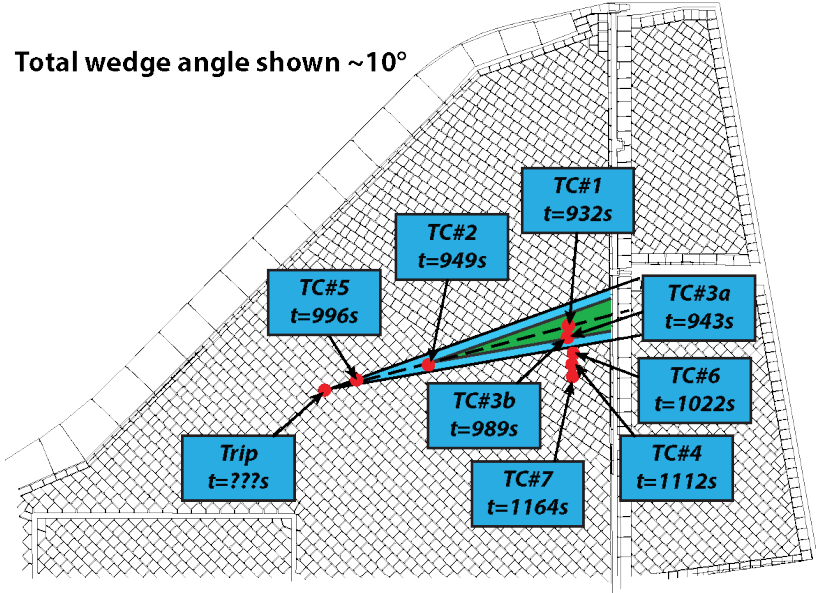

Figure 14. Transition onset times from the BLT FE instrumentation for STS-131. 
the images for STS-128 and 131, both at about the same point in the trajectory, despite the different optics used and atmospheric line-ofsight conditions.

The transition onset times for STS-131, as observed from the standard MADS data, are shown in Fig. 13. This flight experienced fairly late transition times on the acreage, as shown to move forward symmetrically at $\mathrm{t}=1310$ to $1320 \mathrm{~s}$, or roughly Mach 6 . This is close to the latest transition time of any flight (see Ref. 31 for a statistical review of the earlier flights). The post flight runway inspection team noted only minor TPS damage after this flight. It is interesting that it took 3 "tries" to get the "clean" (late BLT) results that the BLT FE team was hoping for, even though significant attention was given to gap fillers after the STS-114 experience. Despite all attempts to control and minimize TPS variability
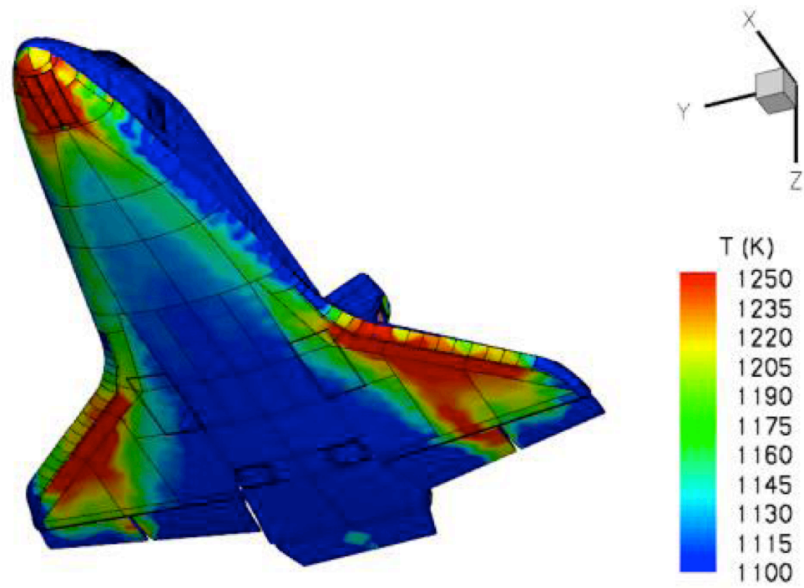

Figure 15. HYTHIRM 3D Mapped Image for STS-133, captured at Mach 18.1. on the Shuttle, tiles/gap-fillers have been shown to be a stubbornly fickle design solution.

The STS-131 transition times determined from the BLT FE thermocouples are shown in Fig. 14. STS-131 TC traces were previously published in Ref. 14. Transition onset at TC\#1 was first observed at $t=932 \mathrm{~s}$ (Mach 17.3) and a fully effective wedge was observed by $996 \mathrm{~s}$ (or Mach 15.6). Similar to the previous flight, the wedge angle is interpreted as being narrow and as such is drawn on Fig. 14 as a 10-deg total angle (as it best represents the cascading transition times). As this was a repeat case, it provides additional evidence to support the validity of the previous observation of a smaller wedge angle at higher Mach numbers.

\section{STS-133}

The fourth BLT FE flight was STS-133, a 12-day mission that landed on March 9, 2011. This mission was the final flight of Discovery (OV-103). The trip height for this mission was $0.5 \mathrm{in}$, with expected transition onset nearer to Mach 19.5 (earlier than prior experience). HYTHIRM supported this mission using the Navy's P-3 Cast Glance, which captured the image shown in Fig. 15 at Mach 18. To the authors' knowledge, STS-133 imaging provided the "highest speed at which calibrated thermal imagery has been obtained on a crewed maneuvering vehicle in the Earth's atmosphere." ${ }^{28}$

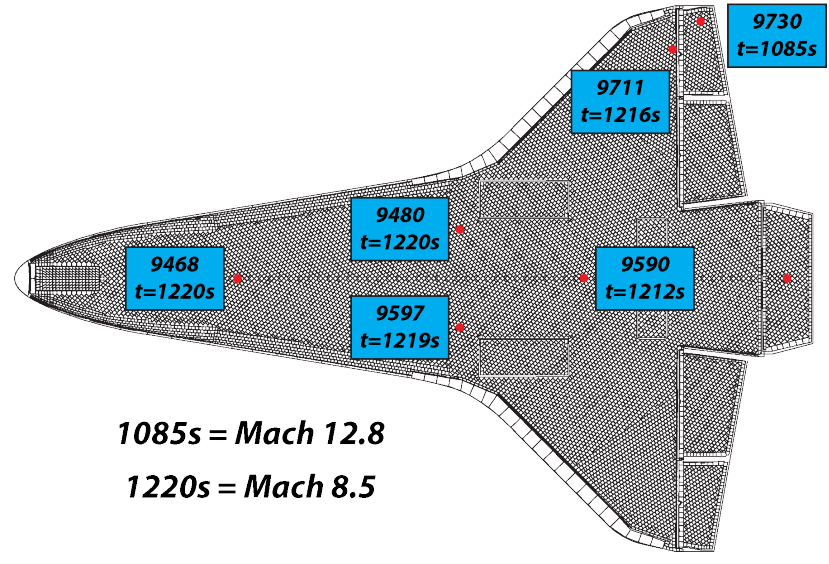

Figure 16. Transition onset times from the MADS data for STS-133.

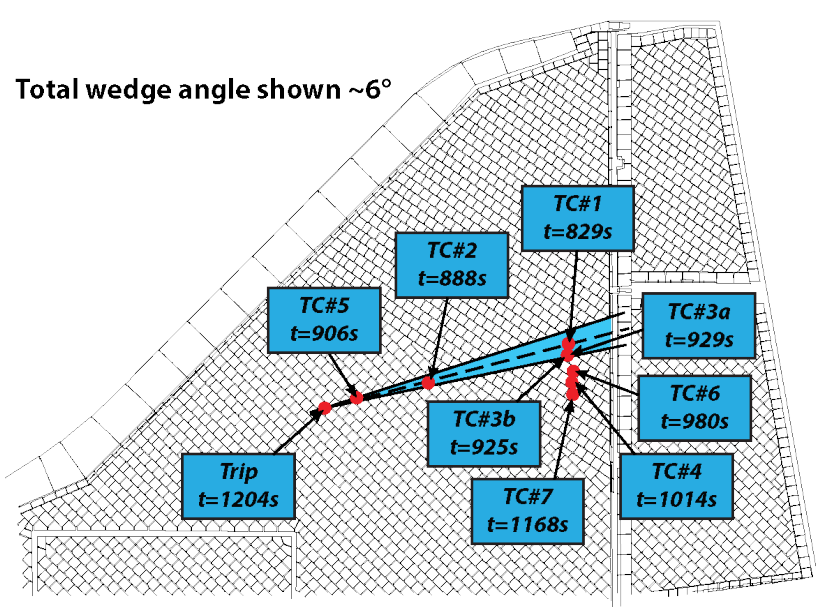

Figure 17. Transition onset times from the BLT FE instrumentation for STS-133. 
The transition onset times for STS-133, as observed from the standard MADS data, are shown in Fig. 16. This was another flight with fairly late and symmetric transition progression on the windward acreage, with transition flashing forward at around 1220s (or Mach 8.5). The post flight runway inspection team only found minor TPS damage, which anecdotally supports the late (nominal) and symmetric transition observations. The attention to detail did not change for the ground crew with the pre-flight TPS processing between these four flights, yet the first two flights experienced relatively early and asymmetric BLT while the next two flights had late and symmetric BLT. It is probably safe to say after 30 years experience with Shuttle TPS performance that tile and gap filler designs are inherently unpredictable.

The STS-133 BLT FE transition times are provided in Fig. 17. The TC traces were also previously published in Ref. 14. Transition onset at TC\#1 was observed at 829 s (or Mach 19.6), while a fully effective wedge was evident by roughly 930 s (or Mach 16.9). Based on the timing of the transition observation at the various TC locations, the wedge does appear to be even narrower than the previous mission, thus a 6-deg total wedge angle is shown.

\section{STS-134}

The fifth and final flight with the BLT FE was STS-134, a 14-day mission that landed on June 1, 2011. This was the one and only BLT FE flight on a different vehicle, this time on Endeavour (OV-105). The trip height for this mission was a repeat of the previous one with a 0.5 in high trip and expected transition onset also near Mach 19.5. STS-134 was supported by HYTHIRM using ground-based MARS imagers located along the western coast of Florida. By virtue of using a large aperture, high-resolution ground-based optical system, the progressive development and movement of the surface thermal response to transition was captured in striking detail, as seen in Fig. 18 (borrowed from Ref. 28 but modified to enhance the contrast in order to better show the turbulent wedges). This time sequence of images depicts transition flashing forward (all due to various discrete trips) on the fuselage as Endeavour slows from Mach 7 at (a), where the vehicle is almost all laminar, to Mach 5.6 at $(\mathrm{f})$, where the vehicle is mostly turbulent. Figure $18(\mathrm{~b})$ even identifies effective transition from a known cavity site (identified on orbit) that is perfectly located between the thermocouples, such that BLT onset was not identified from the onboard instrumentation. This is unprecedented data, both in terms of spatial and temporal coverage. It is possible to identify from the video the time of transition onset such that this case could also be used as a flight cavity calibration case (although it was not done here due to time constraints). Figure 19 provides one of the STS-134 images, which has been 3D mapped, at Mach 6.2.

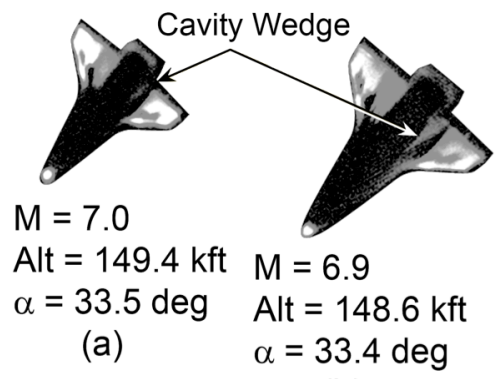

(b)

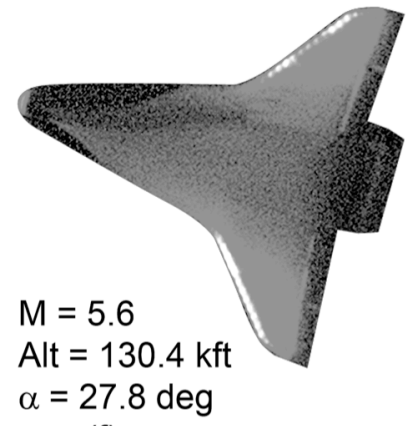

(f)

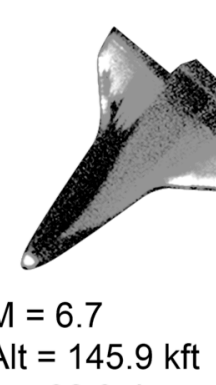

$\alpha=32.9 \mathrm{deg}$

(c)

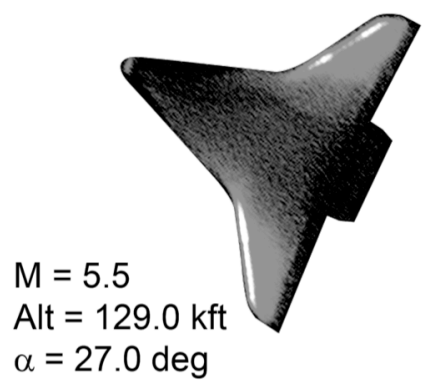

(g)

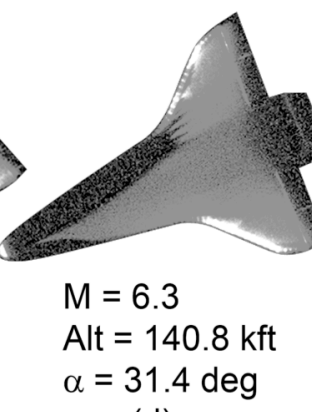

(d)

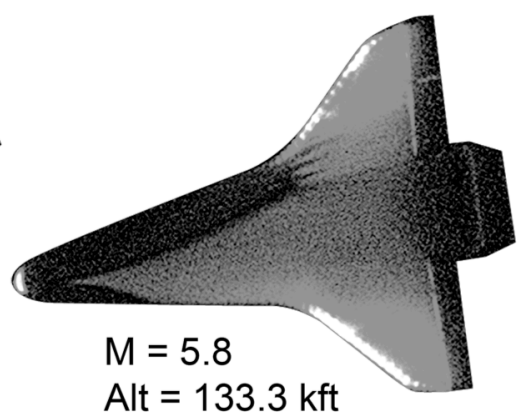

$$
\alpha=28.8 \mathrm{deg}
$$

(e)

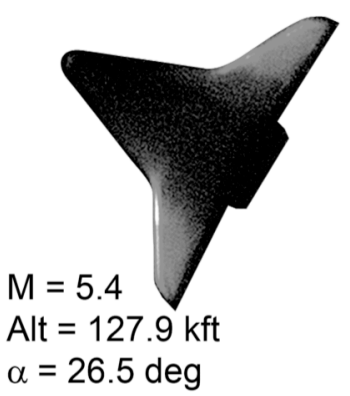

(h)

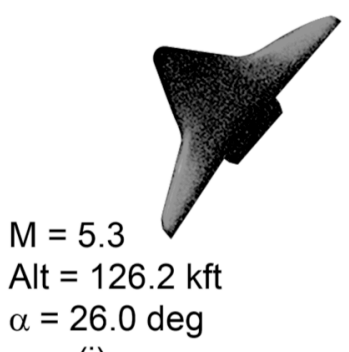

(i)

Figure 18. Evolution of BLT for STS-134 shown in near infrared intensity images. 
Figure 20 provides the standard OV-105 TC results for STS-134, which has added locations due to the switch of vehicles. The ABLT event was observed in the TC data with transition occurring at roughly $t=1270$ s (Mach 6.8 ) on the starboard side. The port side showed transition later, closer to 1330s (or Mach 5.7). The two sources of observation (TC data and HYTHIRM imagery) are in fairly close agreement. Note that the asymmetric transition event observed here is fairly late in the trajectory, even later than the previous two discussed (STS-119 and 128), and as such the size of the protrusion (or cavity) that caused it should be quite small. Since the Shuttle program was nearing the end at the time of this mission, very little energy was expended on tracking down this particular anomalous event.

The BLT FE results from STS-134 are provided in Fig. 21. Note that with the switch to Endeavour for this last flight, only 4 new thermocouples

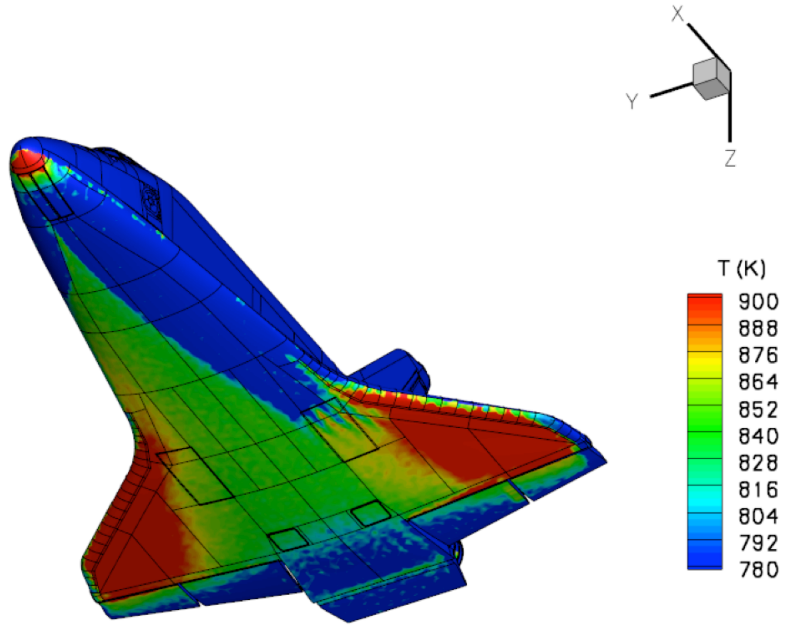
were installed (TC\#1, TC\#5, and 2 on the trip). Transition onset was determined to occur at $\mathrm{t}=840 \mathrm{~s}$ (or Mach 19.4). The TCs needed to determine the wedge angle were not included in this mission, however, a notional 6deg wedge was left on the sketch for reference based on the previous flight. There was some difficulty interpreting the transition onset time for TC\#5, due to anomalous behavior with the thermocouple readings, that have been noted in previous papers ${ }^{13,14}$ and will be discussed further in the next section.

\section{BLT Tool Validation}

Thus far, mainly mission specific observations have been noted and discussed. This section is intended to make comparisons between the five BLT FE results, and then ultimately back to the BLT Tool used for estimating the trip heights for each mission, in order to assess correlation uncertainties.

Strictly from the perspective of determining the performance of the BLT Tool V2, the single most important comparison of results is from resolving BLT onset from TC\#1. Figure 22 provides TC\#1 surface temperature measurements from all five flights. It is important to note that all five flights are flying "similar" trajectories, with only minor trajectory deviations that rarely persist more than a few seconds. All are roughly within a degree of each other in angle of attack, and much less than a degree in yaw, over most of the flight. The only major

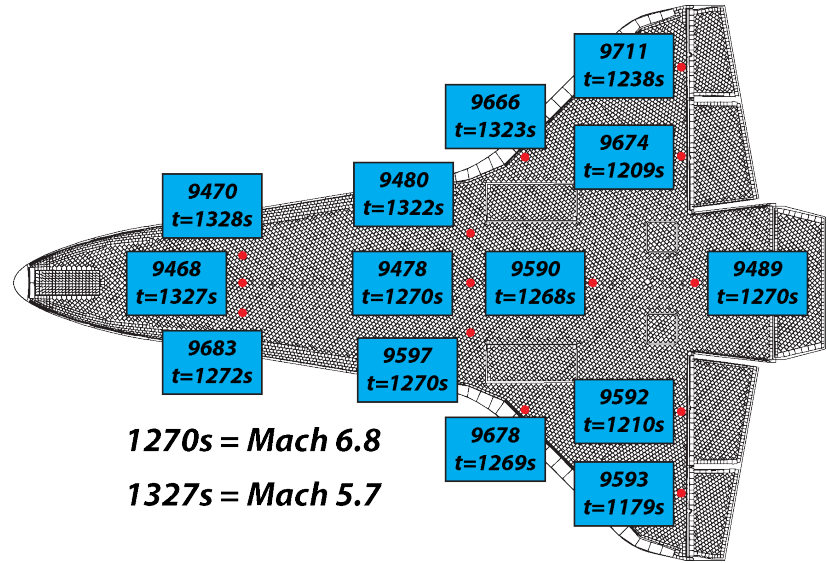

Figure 20. Transition onset times from the MADS data for STS-134.

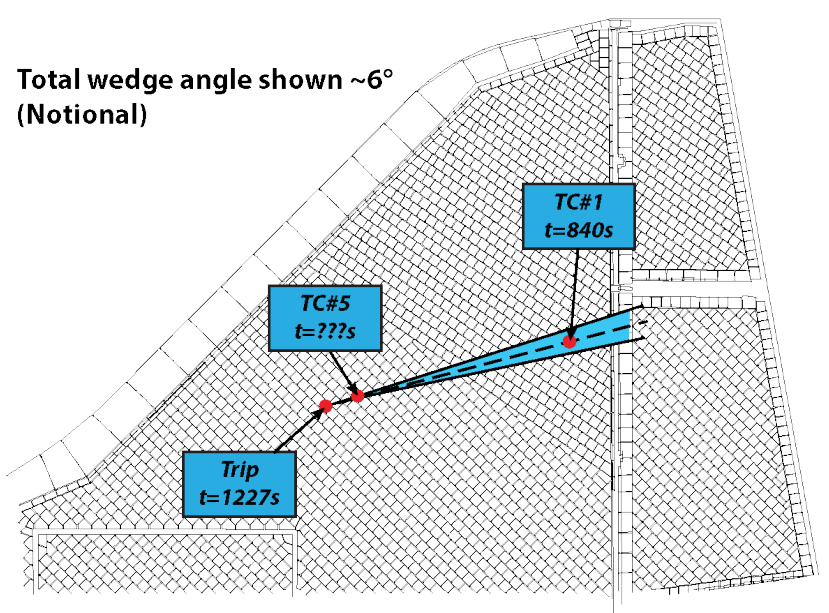

Figure 21. Transition onset times from the BLT FE instrumentation for STS-134. 


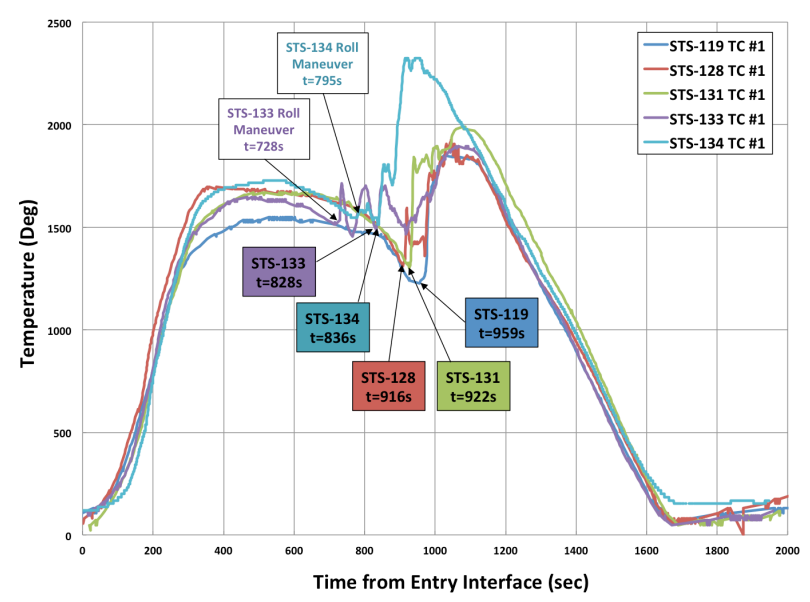

Figure 22. Comparison of TC\#1 for all five BLT FE flights.

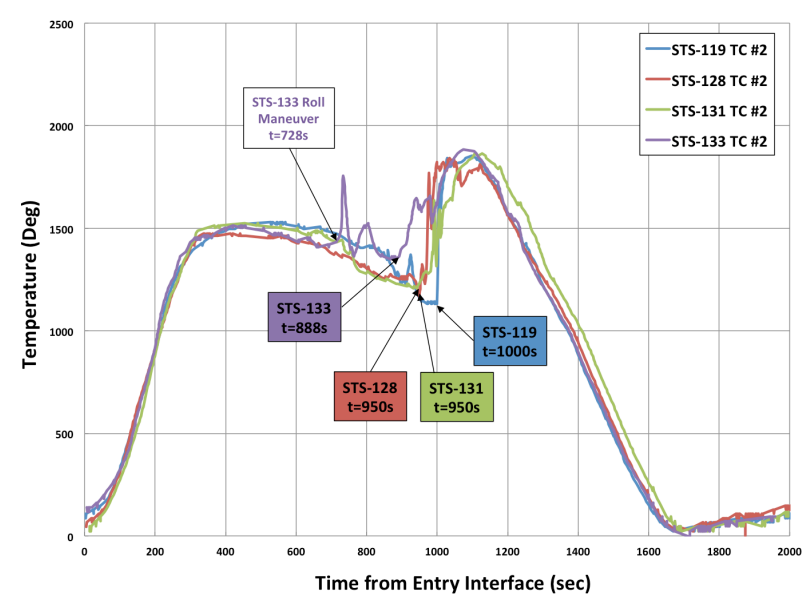

Figure 23. Comparison of TC\#2 for the four OV-103 BLT FE flights.

difference between the five flights is the timing of the energy management maneuvers or what is often referred to as "roll reversal" events (when the vehicle rolls from one side to the other in order to properly vector toward landing). It has been observed that the timing of these roll reversals can directly impact the TC readings, causing wild and unexpected deviations from the normal surface readings. With the above trajectory observations, the similarities of the TC traces, shown in Fig. 22, at the beginning and end are important for anchoring the observation of transition. For instance, TC\#1 initially reveals well-behaved laminar temperatures with time, and then later turbulent temperatures, for all five flights. The point of departure between these two known endpoints, in comparison between the flights, provides the key for assessing the discrete-roughness correlation performance. STS-119, with the smallest trip ( $\mathrm{k}=0.25 \mathrm{in})$, has the latest departure from the laminar "trend", noted in the figure at $\mathrm{t}=959 \mathrm{~s}$. The next largest trip, $\mathrm{k}=0.35 \mathrm{in}$, flown on STS-128 and STS-131, appear to deviate from the laminar trend at similar times, $\mathrm{t}=916 \mathrm{~s}$ and $922 \mathrm{~s}$, respectively. Finally, the largest trips flown, $\mathrm{k}=0.5 \mathrm{in}$, on STS-133 and STS-134, have the earliest "sustained" departure from the laminar trend at roughly the same time of $\mathrm{t}=828 \mathrm{~s}$ and 836s, respectively. The qualifier "sustained" was included for these flights as the timing of roll reversal anomalies are observed in the TC readings at earlier times, but tend to return to "laminar-like" readings.

For some reason (and luckily), the anomalous roll-reversal behavior does not typically affect all thermocouple readings equally, so a secondary location is provided as further evidence of the authors' interpretation of BLT onset, as shown in Fig. 23 for TC\#2. The next best location of interest to the BLT Team was TC\#5, as it provides an assessment of when the trip becomes fully effective (which was the reason it was included on OV-105). Unfortunately, this TC was affected even more by the anomalous behavior (thus not shown). Instead, TC\#2 (located along the assumed wedge centerline between TC\#1 and TC\#5) provides corroboration of the earlier stated trend of well-behaved laminar temperatures, followed by transition onset at set intervals according to the trip height, and then nicely clustered turbulent temperatures. The transition times determined from this location, which is upstream of TC\# 1 and therefore is expected to be delayed in time, are at $\mathrm{t}=1000 \mathrm{~s}$ for $\mathrm{k}=0.25$ in (STS-119), $\mathrm{t}=950 \mathrm{~s}$ for $\mathrm{k}=0.35$ in (both STS-128 and STS-131), and $\mathrm{t}=888 \mathrm{~s}$ for $\mathrm{k}=0.5$ in (STS-133 only). Note that there is a quick roll-reversal deviation for STS-133 that returns back to the laminar levels such that the onset of transition is clearly seen. These well-behaved trends in observation of transition onset and movement forward behind the trip provides further evidence as to the quality of these BLT FE flight results.

With data trends confirmed, the next step in determining uncertainties with implementation of the BLT Tool V2 is to compare the computed boundary layer properties against the original correlations in order to observe the amount of scatter and/or bias away from the curve constant. In a qualitative sense, the correlations have already been shown to perform well just based on a comparison of the predicted transition times (or Mach) to the measured. However, a comparison of the results obtained from the five BLT FE flights to the correlations provides the best assessment of tool performance and uncertainties. 


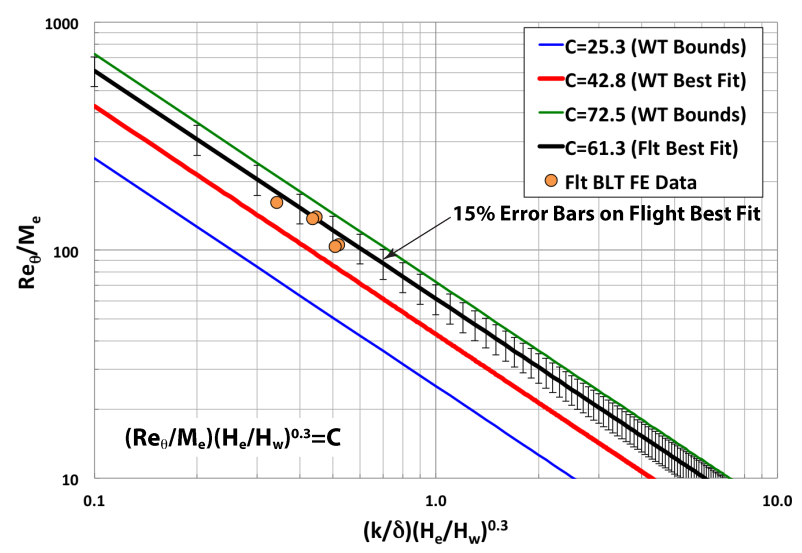

Figure 24. Comparison of BLT FE flight data to the BLT Tool V2 protuberance correlation \#1.

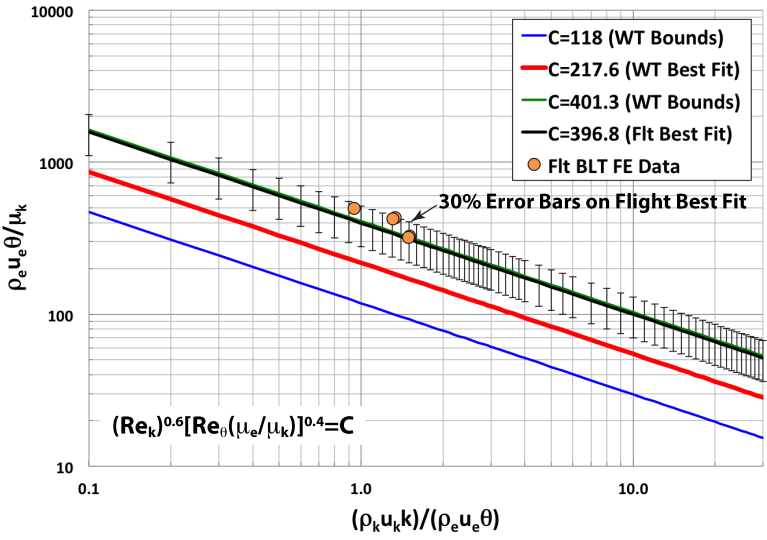

Figure 25. Comparison of BLT FE flight data to the BLT Tool V2 protuberance correlation \#2.

The BLT FE results are compared against both program-accepted BLT Tool V2 protuberance correlations, one based on $\mathrm{Re}_{\theta} / \mathrm{M}_{\mathrm{e}}$ and one based on $\mathrm{Re}_{k}$, in Figs. 24 and 25, respectively. Provided in both plots are the windtunnel-derived correlation curves in color (red for the best fit, blue for the lower bound, and green for the upper bound) and the historical flight derived best-fit correlation in black. The wind-tunnel bounds are mainly included to represent the experimental scatter derived from the extensive database used to establish the correlation and were determined based on $2 \sigma$ regression analysis or $95 \%$ confidence limits (see Ref. 26 for detailed discussion of the experimental database and correlation development). The historical flight-derived curve was developed using the same regression analysis approach but, due to the limited number of acceptable flight cases (10 in total), only the best fit was used. Note that the flight-derived curves are biased towards the upper bound of the wind tunnel data. It was felt that BLT onset predictions based on the wind tunnel results only would be overly conservative due to this bias, thus the correlation curve constants (and bounds) were shifted to match the historical flight best fit (the results shown in Fig. 2). The five BLT FE data points are included on both plots and are shown to be near the historical flight curves. Representative error bars on the flight bestfit curves are shown to illustrate how close these new flight cases fell in comparison to the historical results. In terms of the primary protuberance correlation, based on the $\mathrm{Re}_{\theta} / \mathrm{M}_{\mathrm{e}}$ approach and shown in Fig. 24, $\pm 15 \%$ error bars are shown to capture and contain the five BLT FE results. Note that three out of five of the new data points are actually on the less conservative side of the accepted historical curve. For the secondary correlation, based on the $\mathrm{Re}_{\mathrm{k}}$ approach and shown in Fig. 25, a $\pm 30 \%$ error bar is needed to capture the new BLT FE cases. However, the secondary curve was conservative.

The error bars shown on Figs. 24 and 25 are not intended as representative of the analysis uncertainty of results, only a measure of fidelity in comparison to the correlation constants used in support of the Shuttle program. To assess uncertainties in the BLT FE data, a review of the possible spread in the individual variables that impact the analysis is required. The primary inputs to experimental uncertainty are the trip height and location, and the transition onset time determined from the TC data. Of course, the trip location is fixed and the height has been measured both pre- and post-flight and was generally determined to have less than $1 \%$ surface deviation. Thus, the predominant source of experimental uncertainty for the BLT FE is from the accuracy with which transition onset times are determined. On the order of a $10 \mathrm{~s}$ spread in the interpretation of transition onset times have been observed, depending on the flight and who determines them. The anomalous glitches with the TC data contribute to the spread. A 10 s delta in transition onset time corresponds to less than $4 \%$ change in the BL properties derived from the computational database, which is conservatively represented by the size of symbols shown in both plots. A secondary source of uncertainty is from the computational accuracy of the BL properties obtained via interpolation from the tool database that covers the flight trajectory corridor. It is estimated that no more than $8 \%$ scaling error could occur due to interpolation instead of recalculating properties at mission-specific trajectory points of interest. ${ }^{32}$ The $8 \%$ value represents an upper bound, as it is largely driven by the inaccuracies observed at the shock-shock interaction region at the wing leading edge. Nevertheless, taking these two sources at face value and combining them using root-sum-squares (RSS) would suggest on the order of $9 \%$ uncertainty with these results. 
For the most part, the BLT FE was proposed and developed to reduce the uncertainty associated with the observed bias difference between wind tunnel and flight. As discussed in Ref. 12, there were two BLT-onset related questions to be addressed by the FE, namely could BLT be "initiated with a discrete protuberance at hypersonic nonequilibrium entry conditions" and is there a "ground to flight environment scaling effect on discrete protuberance induced BLT at hypersonic nonequilibrium conditions." The BLT FE results have clearly established that discrete-roughness tripping can occur at nonequilibrium conditions, as is shown by the Mach 19.5 ( $k=0.5$ in) results. Finally, the wind tunnel to flight bias is now shown as a real scaling issue, as the bias can no longer be attributed to ambiguity in our understanding or assumptions of the historical flight cases.

One final note of discussion, it has been suggested in a review that discussed the "Shuttle roughness criteria" approach used here that "the generality of the correlation remains to be determined." ${ }^{33}$ In particular, that review suggested a need for testing in more facilities and a reassessment of several different correlations. The Shuttle RTF BLT Tool effort successfully showed the generality of two discrete roughness correlations to both wind tunnel and flight data in a rigorous fashion, although with unexplained bias between the two. ${ }^{26}$ Now the BLT FE has revealed that the correlations do provide a good representation of trip effectiveness at flight conditions, and that the wind-tunnel to flight bias remains a scaling issue for future flight programs to consider.

\section{Conclusion}

Hypersonic boundary layer transition will continue to be an important aerothermodynamic design consideration for all future high-speed craft. The Shuttle program required a method to predict transition with accuracy as part of the return-to-flight damage assessment capability. The BLT Tool was developed based on ground-based developed correlations, however, an unexplained bias between wind tunnel and flight resulted in unexplained and unacceptable uncertainties. A BLT flight experiment was proposed to help reduce those uncertainties. The BLT FE was flown on five missions and the results were discussed herein. Comparison of the results obtained from those five flights have shown that the correlation methods used as part of the tool were sound, and that the historical flight data were an accurate representation of discrete roughness transition at hypersonic conditions. The BLT FE revealed that tripping at nonequilibrium conditions is possible, and that there is a wind tunnel to flight bias to consider for future applications.

\section{Acknowledgments}

The authors gratefully acknowledge the Shuttle BLT Teams (both V1 and V2), the BLT FE Team, and the HYTHIRM (now SCIFLI) team, which were ad hoc coalitions of academia, industry, and governmental personnel. The list of individuals from these teams is too great to include here, but they know who they are. Additionally, we'd like to thank NESC, JHU-APL, Cast Glance Naval Air Warfare Center, NASA JSC Mission Operations Directorate, MARS Scientific, and NASA KSC for their support.

\section{References}

${ }^{1}$ Wurster, K. E., Riley, C. J., and Zoby, E. V., "Engineering Aerothermal Analysis for X-34 Thermal Protection System Design," JSR vol.36 no.2, pp. 216-228, 1999.

${ }^{2}$ Berry, S. A., Horvath, T. J., Lillard, R. P., Kirk, B. S. and Cassady, A., M., "Aerothermal Testing for Project Orion Crew Exploration Vehicle," AIAA-2009-3842, Jun. 2009.

${ }^{3}$ Choudhari, M., Li, F., and Edwards, J., "Stability Analysis of Roughness Array Wake in a High-Speed Boundary Layer," AIAA Paper 2009-0170, Jan 2009.

${ }^{4}$ Campbell, C., Anderson, B., Bourland, G., Bouslog, S., Cassady, A., Horvath, T., Berry, S., Gnoffo, P., Wood, B., Reuther, J., Driver, D., Chao, D., \& Picetti, D., "Orbiter Return To Flight Entry Aeroheating," AIAA-2006-2917, June 2006.

${ }^{5}$ Berry, S. A., Horvath, T. J., Greene, F. A., Kinder, G. R., and Wang, K. C., "Overview of Boundary Layer Transition Research in Support of Orbiter Return To Flight," AIAA-2006-2918, June 2006.

${ }^{6}$ Horvath, T. J., Berry, S. A., Merski, N. R., Berger, K. T., Buck, G. M., Leichty, D. S., and Schneider, S. P., "Shuttle Damage/Repair from the Perspective of Hypersonic Boundary Layer Transition - Experimental Results," AIAA2006-2919, June 2006. 
${ }^{7}$ Greene, F. A., Hamilton, H. H., “Development of a Boundary Layer Properties Interpolation Tool in Support of Orbiter Return to Flight," AIAA Paper -2006-2920, June 2006.

${ }^{8}$ McGinley, C. B., Berry, S. A., Kinder, G. R., Barnwell, M., Wang, K. C., Kirk, B. S., "Review of Orbiter Flight Boundary Layer Transition Data," AIAA-2006-2921, San Francisco, CA, June 2006.

${ }^{9}$ Berry, S. A., Horvath, T. J., Cassady, A., Kirk, B. S., Wang, K.C., and Hyatt, A. J., "Boundary Layer Transition Results From STS-114," AIAA-2006-2922, San Francisco, CA, June 2006.

${ }^{10}$ Berry, S. A., King, R. A., Kegerise, M. A., Wood, W. A., McGinley, C. B., Berger, K. T., and Anderson, B. P., "Orbiter Boundary Layer Transition Prediction Tool Enhancements," AIAA Paper 2010-0246, Jan 2010.

${ }^{11}$ An, M. Y., Wang, K. C., Campbell, C. H., and Pelley, T. L., "Space Shuttle Orbiter Aerodynamics Induced by Asymmetric Boundary-Layer Transition," AIAA Paper 96-0808, Jan 1996.

${ }^{12}$ Campbell, C. H., Garske, M. T., Kinder, G. R., and Berry, S. A., "Orbiter Entry Boundary Layer Flight Testing," AIAA-2008-0635, Jan. 2008.

${ }^{13}$ Anderson, B., P., Campbell, C. H., Saucedo, L. A., Kinder, G. R., and Berger, K. T., "Boundary Layer Transition Flight Experiment Overview and In-Situ Measurements," AIAA-2010-0240, Jan. 2010.

${ }^{14}$ Berger, K. T., Anderson, B., P., Campbell, C. H., ., Garske, M. T., Saucedo, L. A., Kinder, G. R., and Micklos, A. M., "Boundary Layer Transition Flight Experiment Overview," AIAA-2011-3323, Jun. 2011.

${ }^{15}$ Lee, D. B. and Harthun, M. H., "Aerothermodynamic Entry Environment of the Space Shuttle Orbiter," AIAA Paper 82-0821, June 1982.

${ }^{16}$ Goodrich, W. D., Derry, S. M., \& Bertin, J. J., "Shuttle Boundary-Layer Transition: A Comparison of Flight and Wind Tunnel Data," AIAA Paper 83-0485, Reno, NV, January 1983.

${ }^{17}$ Poll, D. I. A., "Boundary Layer Transition on the Windward Face of the Space Shuttle During Re-Entry," AIAA Paper 85-0899, June 1985.

${ }^{18}$ Hartung, L. C., Throckmorton, D. A., "Computer Graphic Visualization of Orbiter Lower Surface BoundaryLayer Transition," JSR vol.24 no.2, pp. 109-114, 1987.

${ }^{19}$ Bouslog, S. A., An, M. Y., Hartmann, L. N., Derry, S. M., "Review of boundary layer transition flight data on the Space Shuttle Orbiter," AIAA-1991-741, Reno, NV, Jan 1991.

${ }^{20}$ Bouslog, S. A., Bertin, J. J., Berry, S. A., \& Caram, J. M., "Isolated Roughness Induced Boundary Layer Transition: Shuttle Orbiter Ground Tests and Flight Experience," AIAA Paper 97-0274, Jan. 1997.

${ }^{21}$ Berry, S. A. and Horvath, T. J., "Discrete-Roughness Transition for Hypersonic Flight Vehicles," Journal of Spacecraft and Rockets, Vol. 45 No. 2, pp. 216-227, 2008.

${ }^{22}$ Berry, S., Horvath, T., Schwartz, R., Ross, M., Anderson, B., and Campbell, C., "Infrared Imaging of Boundary Layer Transition Flight Experiments," AIAA-2008-4026, Seattle, WA, June, 2008.

${ }^{23}$ Columbia Accident Investigation Board Final Reports, Vols. I-VI [online resource], URL: http://caib.nasa.gov/ [cited Aug and Oct 2003].

${ }^{24}$ Berry, S. A., Bouslog, S. A., Brauckmann, G. J., \& Caram, J. M., "Shuttle Orbiter Experimental Boundary-Layer Transition Results with Isolated Roughness," Journal of Spacecraft and Rockets, Vol. 35, No. 3, 1998, pp. 241-248.

${ }^{25}$ Berry, S. A., and Hamilton, H. H., "Discrete Roughness Effects on Shuttle Orbiter at Mach 6," AIAA Paper 2002-2744, June 2002.

${ }^{26}$ King, R. A., Kegerise, M. A., and Berry, S. A, "Version 2 of the Protuberance Correlations for the ShuttleOrbiter Boundary Layer Transition Tool," NASA/TP-2009-215951, Dec. 2009.

${ }^{27}$ Horvath, T., Berry, S., Alter, S., Blanchard, R., Schwartz, R., Ross, M., Tack, S., "Shuttle Entry Imaging Using Infrared Thermography," AIAA Paper 2007-4267, Jun 2007.

${ }^{28}$ Horvath, T., Zalameda, J., Wood, W., Berry, S., Schwartz, R., Dantowitz, R., Spisz, T., and Taylor. J., "Global Infrared Observations of Roughness Induced Transition on the Space Shuttle Orbiter," RTO Paper MP-AVT-20027, Apr 2012.

${ }^{29}$ Horvath, T., Tomek, D., Splinter, S., Zalameda, J., Krasa, P., Schwartz, R., Gibson, D., Tietjen, A., Berger, K., "The HYTHIRM Project: Flight Thermography of the Space Shuttle During Hypersonic Re-Entry," AIAA Paper 20100241, Jan 2010.

${ }^{30}$ Taylor, J., Spisz, T., Kennerly, S., Gibson, D., Horvath, T., Zalameda, J., Splinter, S., and Kerns, R., "Global Thermography of the Space Shuttle During Hypersonic Re-entry," AIAA Paper 2011-3324, Jun 2011. 
${ }^{31}$ Bouslog, S. A., An, M. Y., and Derry, S. M., "Orbiter Windward-Surface Boundary-Layer Transition Flight Data," NASA CP-3248, Orbiter Experiments (OEX) Aerothermodynamics Symposium, April 1995, pp. 703-739.

${ }^{32}$ Wood, W.A., Alter, S.J., Palmer, G.E., Saunders, D.A., "Allowable Trajectory Variations for Space Shuttle Orbiter Entry-Aeroheating CFD", AIAA 2008-6559, June 2008.

${ }^{33}$ Schneider, S. P., "Effects of Roughness on Hypersonic Boundary Layer Transition," Journal of Spacecraft and Rockets, Vol. 45, No. 2, 2008, pp. 193-209. 